\title{
Kinetic Study of Hydrolysis of Tri-2,5-diethoxy Aniline Phosphate (An Organo Phosphorus Pesticide) in Acid Medium
}

\author{
Alka Tangri \\ Dept. of Chemistry, Brahmanand P.G. College, Kanpur \\ Flat No.- 38 Ram Kuthr 3A/206, Azad Nagar, Kanpur (U.P.), India \\ Tel: 91-983-950-1085Ｅ-mail: anoopt1234@rediffmail.com \\ Pradeep Mishra \\ Dept. of Chemistry, Brahmanand P.G. College, Kanpur \\ 113/115-A, Swaroop Nagar, Kanpur (U.P.), India \\ Tel: 91-983-911-6593 E-mail: pradeepmbnd21@gamil.com \\ Praveen Kumar (Corresponding author) \\ Dayanand, Near the Railway Station Road \\ Rura, Kanpur Dehat (U.P.), India \\ Tel: 91-933-544-9365 E-mail: praveen.dixit007@gamil.com
}

\begin{abstract}
The present work pertains to synthesis, kinetic behavior and mechanism of hydrolysis of some organophosphorus pesticides. The compound investigated here was 2,5-diethoxyaniline in particular. The corresponding tri-phosphate ester was prepared in the laboratory by phosphorylation with $\mathrm{POCI}_{3}$. The process involved is that of the substitution of $-\mathrm{OH}$ group of orthophosphoric acid by aryl radical. The kinetics of the hydrolysis of the above ester was studied in acidic media. The acid employed was HCI. In acidic media, hydrolysis was carried out at three different temperatures 80,90 and $98^{\circ} \mathrm{C}$ (keeping other parameters of the experiment unchanged). The rate of hydrolysis is found to follow the Arrhenius equation. The values of the Arrhenius parameters-energy of activation and change of entropy-point to the bimolecular nature of the hydrolysis of the triester. It can be inferred from the ionic strength data in the range 0.01 to 5 $\mathrm{M}-\mathrm{HCI}$, the reactive species of the present triester is conjugate acid species. Effects of temperature, and solvent on the rate of reaction, together with the correlation of rates with acidity and Bunnett parameters favour bimolecular nature of hydrolysis. The above results lead to the following most probable route of hydrolysis. In the case of triesers, dioxane was already present as constituent of the solvent. Experiment was repeated at three different dioxane concentrations in each case. The analysis of these data led to the interpretation that a transition state is formed with charge dispersed out of the reactive species and water and that the hydrolysis is a bimolecular nucleophilic reaction. The theoretical part of the present work includes calculation of the various terms involved in the mathematical formation of Hammett, Zucker and Hammett, Bunnett and Bunnett and Olsen hypothesis. This part supports the interpretation of the experiment results regarding the molecularity of the reaction.
\end{abstract}

Keywords: Organo phosphorus pesticide, Hydrolysis, 2,5-diethoxy aniline, Acid conjugate acid species

\section{Introduction}

Hydrolysis of an ester ${ }^{1}$ may proceed either through $\mathrm{S}_{\mathrm{N}}{ }^{1}$ or $\mathrm{S}_{\mathrm{N}}{ }^{2}$ path depending on its structure and the set of experimental conditions used. Many solvents may be used as nucleophilic reagents. A large excess of concentration is made of these solvents so that the rates are independent of their contribution. The following three factors are required to be determined for arriving at the most suitable mechanism of hydrolysis of an ester,
(a) reactive species
(b) molecularity 
(c) bond rupture

The reactive species ${ }^{2}$ may be neutral, protonated (or, conjugate acid, dinegative forms. Rarely has an additional species been observed which is termed as protonated neutral form (i.e. - $\mathrm{O}_{+}^{+}-\mathrm{CH}_{3}$ )
e.g., in dimethoxy phenyl phosphate esters.

Molecularity may be either uni - or bimolecular, eventhough hydrolysis is basically a double decomposition reaction between substrate ester and water. Bond rupture in these phosphate esters be $\mathrm{C}-\mathrm{N}$ or $\mathrm{P}-\mathrm{N}$, the latter is usually predominant, especially in aromatic orthophosphate esters, when the leaving group is a nitro group.

Different reactive forms of an aryl orthophosphate ester may be illustrated as follows in the cases of triesters.

Triester

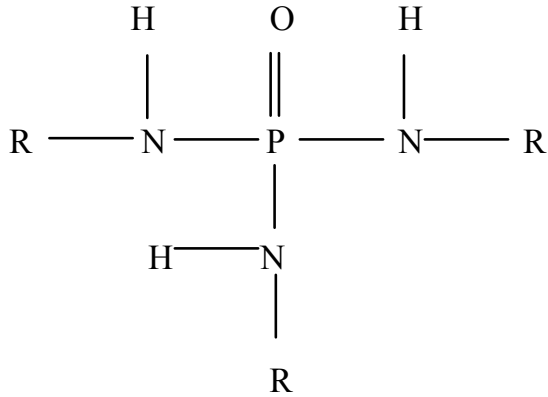

(Neutral Form)

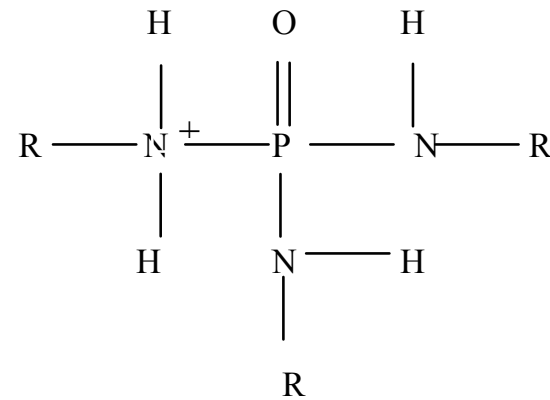

(Conjugate acid form)

The three factors given earlier together with other ideology governing reactivity cited in sections previously are investigated for drawing a plausible reaction course leading to hydrolytic products. The suggestion implying the formation of an activated complex or a critical state or, more precisely, a transition state in an endothermic chemical reaction may also have to be invoked as one of the tests confirming the reaction to be $\mathrm{S}_{\mathrm{N}}{ }^{2}$ one. Something of the kind of a last word for the mechanism of a given reaction can never be given. All one can generalise is a most appropriate mechanism based on the latest facts.

Eight reaction pathways for triester hydrolyses may be concenived of, theoretically. Acid catalysed and base catalysed hydrolyses may involve two more additional reaction paths making the total to ten for triesters. In practice, however, most of these reaction mechanisms will be non-trackable.

\section{Literature Review}

Organophosphate esters are the derivatives of orthophosphoric acid and infinite raminifications are possible by making changes in subsistent groups attached to phosphorus atom through specific linkages such as $\mathrm{C}-\mathrm{N}-\mathrm{P}^{3-7}, \mathrm{C}-\mathrm{O}-\mathrm{P}^{8-14}$. Hence, they constitute a large family, which display a great role in the biological, industrial agricultural, medicinal and academic field. The multidimentional importance of organophosphate esters leads to vigorous research and development, which may be reviewed under different heads.

Orthophosphate esters comprise a group of mono- di- and triesters depending upon the presence of two, one and none hydroxy group in the phosphate part respectively. The literature providing informations about these esters can be reviewed as below: The hydrolysis of tri-esters has been studied to a little extent. The very early approach towards the kinetic investigation of the hydrolysis of tri-ester has been done by Cavalier ${ }^{15}$. Drusnel ${ }^{16}$, Plimmer, Burch ${ }^{17}$ and Bailly $^{18}$ studied the hydrolysis of tri-esters in alkaline medium at room temperature and they were able to get corresponding diesters, which resist alkaline hydrolysis at low temperature.

Bluemethal and herbert ${ }^{19}$ used $\mathrm{H}_{2} \mathrm{O}$ and showed that alkaline hydrolysis of trialkyl phosphate involve $\mathrm{P}-\mathrm{O}$ bond fission. Later on Bunton et. $\mathrm{al}^{20}$ found that the $\mathrm{P}-\mathrm{O}$ bond fission also occurs in the hydrolysis of aromatic tri-esters.

Thain ${ }^{21}$ studied hydrolysis of triethyl phosphorotrithioate and tri ethyl phosphate in neutral, acidic and alkaline medium. The alkaline hydrolysis of thiol ester involve $\mathrm{P}-\mathrm{S}$ bond fission in $50 \%$ dioxan at $250 \mathrm{C}$. The reaction was shown to be molecular and mechanism involve attack of the hydroxide ion on phosphorus atom. The rate of hydrolysis of thiol ester was found 15 hundred times faster than that of oxygen-ester. it was attributed to the more rigid transition state in the latter, Lower values of Arrhenius parameters and lower entropy of activation were taken to signify rigidity of the transition state. It was also supported by the work of Schaefgen ${ }^{22}$, Rylander and Tarbell ${ }^{23}$ Hudson and Keavy ${ }^{24}$. 
Bunton and co-workers ${ }^{20}$ gave a more detailed and systematic kinetic investigation of trimethyl and triphenyl phosphates, both involve $\mathrm{P}-\mathrm{O}$ bond fission but in water, cleavage of $\mathrm{P}-\mathrm{O}$ bonds occurs via different mechanism. They reported that the triphenyl phosphate hydrolyse faster than trimethyl phosphate in $75 \%$ dioxan at $35^{\circ} \mathrm{C}$. The difference in the reactivity is due to the different stablity of phenoxide and methoxide ions. The rate in case of trimethyl phosphate are not much suffered by solvent changes $\left(\mathrm{K}_{2}\right.$ in water $-2.01 \times 10^{-2} \mathrm{~mol} . \mathrm{dm}^{-3} \mathrm{~min}^{-1}$ and $\mathrm{K}_{2}$ in $75 \%$ dioxan $=1.48 \times 10^{-2} \mathrm{Mol} . \mathrm{dm}^{-3} \mathrm{~min}^{-1}$ ) at $35^{\circ} \mathrm{C}$. The mechanisms involve nucleophilic bimolecular attack of hydroxide ion on the phosphorus atom. Aromatic neucleophilic substitution is known to proceed readily, when the benzene ring contains strongly electrons attracting groups ${ }^{25}$, in neutral solutions, trimethyl phosphate involve $\mathrm{C}-\mathrm{O}$ bond fission.

Mhala and co-workers ${ }^{10}$ studied the bydrolysis of simple and substituted phosphate tri-esters such as tri-allyl ${ }^{26}$. Their mechanisms in neutral and buffer solutions have been studied. The path of hydrolysis involves neutral and protonated. Form, Neutral species is proved to be comparatively less reactive. A bimolecular reaction was supported by temperature and solvent effect on the rate of hydrolysis. Bourne et.al ${ }^{27}$. Kasparek and Frantisek ${ }^{28}$ gave a single step mechanism for the basic hydrolysis of $\mathrm{N}$-substituted phosphoryl triamides in aqueous $\mathrm{NaOH}$. A convenient synthetic route to phosphate esters from phospites was developed by Pandey, Batra and Pant ${ }^{29}$. Cevasco and Thea ${ }^{30}$ carried out alkaline hydrolysis of N, N-diethyl p-(3, 5- dimethyl -4-hydroxy phenyl) phosphoramidic chloride. Gupta ${ }^{31}$ kinetically studied the hydrolytic transformation of mono-o-nitro-p- methoxy aniline orthophosphate and the data showed $\mathrm{P}-\mathrm{N}$ bond fission.

R, Patil (Mhala), Shinde et. al, ${ }^{32}$ kinetically studied the hydrolysis of mono phenylhydrazophosphate at $98^{0} \mathrm{C}$. Kalamse et $\mathrm{al},{ }^{33}$ studied the dielectric relaxation, dipole moment and thermodynamic parameters for binary mixtures in 1 , 4-dioxane solution. Sharma et. al, ${ }^{34}$ studied the oxidation of lower oxyacids of phosphorus by quinoline bromochromate (QBC) in DMSO leads to the formation of corresponding oxyacids with phosphorus in a higher oxidation state. Chaurasia $^{35}$ studied the kinetics of hydrolysis of 4-bromoaniline-phosphoro mono-amidate, which is a substituted ester of orthophosphoric acid in acid concentration range 1.0-6.0 $\mathrm{M}$ of $\mathrm{HCl}$ at $70^{\circ} \mathrm{C}$.

\section{Experimental}

\subsection{Preparation of the Compounds}

The preparation of phosphate esters 2, 5-diethoxyaniline on which the kinetic study has been done involves direct reaction of $\mathrm{POCl}_{3}$ with 2, 5-diethoxyaniline.

\subsection{Preparation of Tri-2,5-diethoxyaniline phosphate}

Tri-2,5-diethoxyaniline phosphate was prepared by the same method as di-2,5-diethoxyaniline phosphate ester, with a little modification in the process.

14 gms of 2,5-diethoxyaniline was dissolved in $15.8 \mathrm{ml}$ of pyridine. This solution was stirred and heated for about an hour, followed by gradual addition of $5.5 \mathrm{ml} \mathrm{POCl}_{3}$ in about half an hour. The whole solution was then continuously stirred and heated for nearly 8 hours till a forming a viscous mass was formed. It was then dried and treated with large amount of water. As a result, pyridine hydrochloride and acid esters were soluble leaving behind insoluble tri-2, 5-diethoxyaniline phosphate ester.

It was further treated with $5 \% \mathrm{NaOH}$ solution a number of times. It was then thoroughly washed with water and dried. Triester was recrystallised from reactified spirit and water.

Results of Elemental analysis

\begin{tabular}{|c|c|c|}
\hline Elements & Observed & Calculated \\
\hline Carbon & $60.13 \%$ & $61.43 \%$ \\
\hline Nitrogen & $5.50 \%$ & $7.16 \%$ \\
\hline Phosphorus & $4.41 \%$ & $5.29 \%$ \\
\hline
\end{tabular}

\subsection{Colorimetric Estimation of Inorganic Phosphates}

Phosphate esters, on hydrolysis, produce inorganic phosphates and its quantitative estimation was made possible by Allen's modified method ${ }^{36}$. The inorganic phosphates react with ammonium molybdate and forms a phosphomolybdate complex $\left[\left(\mathrm{NH}_{4}\right)_{3} \mathrm{PO}_{4} 12 \mathrm{MoO}_{3}\right]$, which is reduced to molybdate blue, a soluble complex by addition of a mixture, of 2,5-diethoxy phenol hydrochloride (Amidol, diamol or nerol) and sodium metabisulphite solutions. The blue colour took 10 minutes to reach its maximum intensity and then remained stable for next 30 minutes. The intensity of blue colour is directly proportional to the amount of free phosphoric acid. It is independent of temperature upto $25^{\circ} \mathrm{C}$. The optical density of the colour so produced was measured by a single cell type "Synstronix" photoelectric colorimeter fitted with a red filter (Kodak-608 $\mu$ ). The solutions brought in use for carrying out the colorimetric estimation of inorganic phosphate 


\subsection{Calibration of Photoelectric Colorimeter}

A standard solution potassium dihydrogen phosphate was used to calibrate "Systronix" type colorimeter $1.0968 \mathrm{~g}$. of potassium dihydrogen phosphate was dissolved in $250-\mathrm{ml}$ distilled water. $5.0 \mathrm{ml}$ of this solution having $1.0 \mathrm{mg}$ of phosphorus per $\mathrm{ml}$ was diluted 50 times. The second solution so obtained containing $0.02-\mathrm{mg}$ phosphorus per $\mathrm{ml}$ used to calibrate the instrument. In each run, a known volume $(0.5-7.0 \mathrm{ml})$ of standard solution, $2.0 \mathrm{ml}$ of $10 \mathrm{M}-\mathrm{HCl}, 2.0 \mathrm{ml}$ of amidol reagent and $1.0 \mathrm{ml}$ of ammonium molybdate ware taken in a $25 \mathrm{ml}$ standard flask and the volume was made upto the mark with distilled water. Optical density of blue colour so obtained was plotted against $\mathrm{mg}$ of phosphorus present as inorganic phosphate.

\subsection{Acid hydrolysis of triester}

Concentration of Tri-2,5-diethoxyaniline phosphate $\quad 0.0005 \mathrm{M}$

\section{Medium}

Temperature

$$
3 \mathrm{M}-\mathrm{HCl}
$$

Solvent

$$
98 \pm 0.5^{0} \mathrm{C}
$$

Infinite reading $(\propto)$

$$
30 \% \text { Dioxane }
$$

$0.0148 \mathrm{~g}$. of triester was dissolved in $15-\mathrm{ml}$ dioxane in a $50-\mathrm{ml}$ flask, $13 \mathrm{ml}$ of cooled $11.5 \mathrm{M}-\mathrm{HCI}$ was added to the above cooled solution. It was then made upto the mark by the addition of distilled water and transferred into a 100-ml flask. The flask was then stoppered and suspended in a thermostat maintained at $98 \pm 0.5 \mathrm{C}$.

$5 \mathrm{ml}$ of aliquots were pipetted out and developed the blue colour as described earlier. The optical density of blue colour was measured by colorimeter. The values obtained have been recorded in table -1 .

\section{Results and Discussion}

The triester was also synthesised and its mechanism of hydrolysis studied on the basis of study in acid and $\mathrm{pH}$ media. Absence of free-OH group makes its hydrolysis different from its mono-and dinegative species. Only two reactive species are possible; netural species or in the form of its conjugate acid species.

Kinetic study of the hydrolysis of tri-2,5-diethoxyaniline phosphate was studied in detail both in acid region (0.01-5 M $\mathrm{HCI})$ and buffers $(\mathrm{pH} 1.24-7.46)$ in $30 \%$ aqueous-dioxane at $98^{\circ} \mathrm{C}$. The concentration of triester was kept as $5.0 \times 10^{-4}$ $\mathrm{M}$ throughout the kinetic investigations. First order rate coefficients were determined using integral form of rate equation of the corresponding type. Estimation of inorganic phosphate obtained was made by Allen's method ${ }^{36}$, where a blue complex results.

The hydrolysis of the triester is, therefore, more complex as compared to that of the corresponding mono-and diesters. Various effects due to the addition of neutral electrolyte, temperature, concentration and solvent have been applied to determine and support the contributory reactive forms, types of acid catalysis, formation of reactive intermediates as well as order of hydrolysis. In acid range, various criteria (Hammett, Zucker and Hammett, and Bunnett et al) have been employed to establish order and molecularity of the reaction. Bond fission and other details were studied using comparative kinetic rate data of other triesters whose mechanisms are well established.

\subsection{Hydrolysis Via Conjugate Acid Species}

In order to understand the behaviour of tri-2,5-diethoxyaniline phosphate during hydrolysis, i.e., involvement of its reactive forms as well as their mode of hydrolysis, kinetic runs were performed in 0.01 to $5 \mathrm{M} \mathrm{HCI}$ at $98^{\circ} \mathrm{C}$ in $30 \%$ aqueous dioxane $(\mathrm{v} / \mathrm{v})$. Table-2 and fig.-I records the first order rate coefficients.

In acid region, the rate rises with rise in acidity, passing through a maximum at $4 \mathrm{M}$, and then falling down. The initial rise in rate may either be due to incursion of acid catalysed hydrolysis (conjugate acid species) or to the positive effect of ionic strength or due to both. The lowering in rate after $4 \mathrm{M}$ may be due to negative effect of ionic strength or due to water activity or due to maximum protonation of triester. Such a maximum has been found in amide system ${ }^{37,38}$ which are sufficiently basic to get protonated to maximum extent.

\subsubsection{Kinetic salt effect}

In order to understand the behaviour of triester, it was subjected to constant ionic strength effect studies. For this, appropriate molarities of HCI and NaCI were taken. Table-3 and fig-II records the results based on experimental rate data shows three straight lines, each for a different value of $\mu$, meeting at a point on the rate axis showing thereby a constant contribution of hydrolysis via neutral species.

A totally different behaviour of the triester is observed by the decreasing slopes with the increase in $\mu$. It suggests a negative ionic strength effect on the acid catalysed rates in the acid range. Each of the lines may be represented by,

$$
\mathrm{K}_{\mathrm{e}}=\mathrm{K}_{\mathrm{H}}^{+} \mathrm{C}_{\mathrm{H}}^{+}
$$


Where, $\mathrm{K}_{\mathrm{e}}, \mathrm{K}_{\mathrm{H}}{ }^{+}$and $\mathrm{C}_{\mathrm{H}}{ }^{+}$are the experimental acid catalysed rate, specific acid catalysed rate at that ionic strength $\mathrm{C}_{\mathrm{H}}{ }^{+}$ and hydrogen ion concentration respectively. Fig.-III describes the linear plot of log acid rate $\mu$ data as recorded in table-4.

The above linearity confirms the validity of second emperical equation of Debye-Huckel theory ${ }^{39}$

$$
\mathrm{K}_{\mathrm{H}}{ }^{+}=\mathrm{K}_{\mathrm{Ho}}{ }^{+} \exp \left(\mathrm{b}_{\mathrm{H}}{ }^{+}+\mu\right)
$$

Where, $\mathrm{K}_{\mathrm{Ho}}{ }^{+}$is the specific acid - catalysed rate at zero ionic strength, $\mathrm{b}_{\mathrm{H}}{ }^{+}$is a constant and $\mu$ is the ionic strength. Equation (2) can be written as,

$$
\log \mathrm{K}_{\mathrm{H}}^{+}=\log \mathrm{K}_{\mathrm{Ho}}^{+}+\mathrm{b}_{\mathrm{H}}^{+} \mu
$$

where, $\mathrm{b}_{\mathrm{H}}{ }^{+}=\mathrm{b}_{\mathrm{H}}{ }^{+} / \log _{\mathrm{e}} 10$. Intercept on the log-rate axis of the fig.-III is $5+\log \mathrm{K}_{\mathrm{Ho}}{ }^{+}$and equals 1.98 . The slope is $\mathrm{b}_{\mathrm{H}}{ }^{+}$ $-0.07$

On combining equations (1) and (2)

$$
\mathrm{K}_{\mathrm{e}}=\mathrm{K}_{\mathrm{Ho}}{ }^{+} \mathrm{C}_{\mathrm{H}}^{+} \exp \left(\mathrm{b}_{\mathrm{H}}{ }^{+} \mu\right)
$$

The total rates are obtained by adding to these rates the neutral rates $\left(2 \times 10^{-3} \mathrm{mon}^{-1}\right)$.

$$
\mathrm{K}_{\mathrm{e}}=\mathrm{K}_{\mathrm{H}}^{+} \mathrm{C}_{\mathrm{H}}^{+}+\mathrm{K}_{\mathrm{N}}
$$

The results of this calculation are summarized in table-4. It can be seen that the calculated and experimental rates are in good agreement.

The experimental and calculated rates at $4.5 \mathrm{M}$ shows disparity. In all the aryl orthophosphate esters, the rates rise upto a particular acid molarity ( $4 \mathrm{M}$ being usual) and then show a substantial fall. In this respect, this ester also behaves in a similar manner and is expected to involve similar kinds of changes. Most probable account for the decline in rates after the maximum, can be accounted for,

(a) the decrease in the contribution of the neutral species, if at all present,

(b) the decrease in the concentration of the nucleophile $\left(\mathrm{H}_{2} \mathrm{O}\right)$ in a bimolecular reaction after the maximum ${ }^{40}$, and

(c) a negative ionic strength effect ${ }^{41}$ on the reactive form involved.

The last two of the above are expected to be more likely because the contribution of the neutral form is almost constant in the entire acid range. Negative ionic strength effect alone, based on ionic strength data of the triester, is incapable of explaining the disparity in rates beyond $4 \mathrm{M}$. Water activity ${ }^{40,42}$ term is, therefore, used to give a more appropriate rate expression for computing rates beyond $4 \mathrm{M}$. It is based on a modified form a Bronsted-Bjerrum equation ${ }^{43}$ and is given below,

$$
\mathrm{K}_{\mathrm{e}}=\mathrm{K}_{\mathrm{Ho}}{ }^{+} \mathrm{C}_{\mathrm{H}}^{+} \exp \left(\mathrm{b}_{\mathrm{H}}{ }^{+} \mu\right)\left(\mathrm{a}_{\mathrm{H}_{2} \mathrm{O}}\right)^{\mathrm{n}}
$$

where, $a_{H_{2} \mathrm{O}}$ represents water activity term and $\mathrm{n}$ is an integer. In the present triester $\mathrm{n}, 1$ and 2 cover the entire range satisfactorily. It indicates participation of a single or a cluster of a maximum of two water molecules for its conversion into the corresponding transition state. It can, therefore, be concluded that both neutral and conjugate acid species are reactive. The contribution of the neutral species to the overall hydrolysis is constant while conjugate acid species is subject to the negative salt effect. The maximum in log rate- (acid, $\mathrm{pH})$ profile is owing to the effect of water activity.

\subsubsection{Hammett acidity function}

The involvement of water molecule in the hydrolysis of tri-2,5-diethoxyaniline phosphate can be verified using correlations of various types. Firstly, the Hammett correlation ${ }^{44}$ based on the available data table- 6 is presented in fig.-IV under the assumption that protonation of the substrate is accurately represented by the $\mathrm{H}_{0}$ function. The slope of the plot $(0.30)$ suggests that water is also involved in the slow step leading to the hydrolytic products.

Zucker and Hammett ${ }^{45}$ plot indicates another criterion to determine the participation of water as a second reaction partner. It is based on the reasoning that the expected rates vary in approximate proportion to $\mathrm{C}_{\mathrm{H}}{ }^{+}$. The plot as shown in fig.- $V$ has a slope 0.40 does not allow to consider the involvement of water for the present reaction. It is clear from the ionic strength data that the acid-catalysed rated are lowered by the effect of the negative ionic strength. It may be one of the reasons for the low value of the slope (0.40) of the Zucker-Hammett plot. Fig.- V obtained on plotting $\log \mathrm{K}_{\mathrm{H}}{ }^{+} \mathrm{C}_{\mathrm{H}}{ }^{+}-$ $\mathrm{b}_{\mathrm{H}}{ }^{+}+\mu$ against log acid molarity (shown by the dotted lines) has unity slope (1.0). The reaction may, therefore, be taken to be bimolecular. Table- 6 presents the data for Zucker-Hammett plot.

\subsubsection{Bunnett parameters}

Few exceptions were observed in Zucker-Hammett hypothesis with the advancement in this field. It was then modified Bunnett ${ }^{46}$ and further by Bunnett and Olsen ${ }^{47}$, Fig.-VI describes Bunnett plots. In one, $\log \mathrm{K}_{\mathrm{e}}+\mathrm{H}_{0}$ is plotted against $\log \mathrm{a}_{\mathrm{H} 20}$. The slope of this linear curve (w) is 9.09. Another plot depicted in the same figure is between $\log \mathrm{K}_{\mathrm{e}} \log \mathrm{C}_{\mathrm{H}}^{+}$ and $\log \mathrm{a}_{\mathrm{H}_{2} 0}$ have a slope $\left(\mathrm{w}^{*}\right)$ of magnitude 3.75. According to Bunnett, the reaction may be bimolecular if the value of 
$\mathrm{w}$ exceeds 3. In the present case the value of $\mathrm{w}$ and $\mathrm{w}^{*}$ are 9.09 and 3.75 respectively favouring the bimolecular nature of hydrolysis, Table- 6 records the data for the above plots.

Another parameter $\phi$, introduced by Bunnett and Olsen ${ }^{46,47}$ is obtained from the plot of log $\mathrm{K}_{\mathrm{e}}+\mathrm{H}_{0} \mathrm{vs}-\left[\log \mathrm{C}_{\mathrm{H}}^{+}+\mathrm{H}_{0}\right]$, Fig.-VII illustrates such a plot drawn from the data of table- 6 . The value of $\phi=1.48$ for the present triester indicates the dependence of rate on both acidity and water activity ${ }^{48}$. In case of higher acid molarities ( $\left.>4 \mathrm{M}-\mathrm{HCI}\right)$, show that the agreement between the estimated and observed rates occurs only when the dependence of rate on water activity is taken into consideration.

\subsubsection{Temperature effect}

Further evidences regarding molecularity and rigidity of transition state with probable mechanism of hydrolysis can be obtained by Arrhenius parameters. In order to determine Arrhenius parameters for the acid catalysed hydrolysis of triester, a series of kinetic runs were carried out at various temperatures. Temperature effect was examined at two acid molarities with a view to find out whether or not is there a maximum protonation. The effect was studied at $3 \mathrm{M}$ and 5 M-HCI. Unlike amides, no significant variations of Arrhenius parameters were noticed proving the absence of protonation. Rate coefficients are presented in table-8.

Fig.-VII shows the Arrhenius plots. Linearity of the two curves show the validity of Arrhinius equation ${ }^{49,50}$.

Table-9 records the values of Arrhenius parameters at $3 \mathrm{M}$ and $5 \mathrm{M}$-HCI. The results show that the activation energy in very low and the entropy of activation is highly negative. Such results are expected when transition state of reaction has more rigid nature due to hydrogen bonding with solvent molecules. Similar results were observed by Bunton for the hydrolysis of nitrophenyl phosphate ${ }^{43}$. It may, therefore, be emphasised that the Arrhenius parameters for the acid catalysed hydrolysis of this triester is bimolecular and indicate the formation of highly solvated transition state.

\section{Conclusion}

The analysis of these data led to the interpretation that a transition state is formed with charge dispersed out of the reactive species and water and that the hydrolysis is a bimolecular nucleophilic reaction. The theoretical part of the present work includes calculation of the various terms involved in the mathematical formation of Hammett, Zucker and Hammett, Bunnett and Bunnett and Olsen hydpothesis. This part supports the interpretation of the experiment results regarding the molecularity of the reaction.

The bimolecular attack of water on phosphorus the ester under investigation is taken to proceed via P-N bond fission. Isokinetic relationship plots among the same type of ester support this particular rupture. Based upon this, complete hydrolytic mechanisms are postulated.

\section{References}

Allen. R.J.L. (1940). Biochem. J., 34, 858.

Bailley. M.C. (1942). Bull. Soc. Chim., France, 9, 340, 405.

Bailly and Gaume. (1935). Bull, Soc., Chem, 2, 354.

Bluementhal and Herbet. (1945). Trans, Faraday, Soc., 41, 611.

Bourne. N. (1984). Williams, A., Douglas, K.T. and Penkava, T.R. "Perkin Trans" II, No. 11, 1827.

Bunnett and Olsen. Canad. (1966). J. Chem. 44, 1917.

Bunnett. J.F. (1961). J. Amer. Chem. Soc., 83, 4956.

Bunton. C.A. (1958). Llewellyn, D.R., Oldham, K.G., and Vernon, C.A. J. Chem. Soc., 1955, 3641, 3588.

Bunton. C.A. (1963). Nucleophilic substitution at a saturated Carbon atom. Blsevier Publishing Co., N.Y.

Bunton. (1966). C.A. Barnard, P.W.C. Kellerman, D., Mhala, M.M., Silver, B., Vernon, C.A. and Welch, V.A. J. Chem. Soc., Sec. B. Physical Organic Chemistry, 227-235.

Cavalier. Compt. rend. (1898). Hebd, Seanc. Acad. Scie., Paris, 127, 114.

Cevasco. Giorgio and Thia Sergio. (1991). J. Org. Che., 56, 72-74.

Chaturvedi. (Miss) Kumud. (1999). Ph.D. Thesis, Dr. B.R. Ambedkar Univ. Agra.

Chourasia. N.R.K. (2001). Bhadauria, A.K.S. and Shivhare, R.L. Asian. J. Chem., 13(4). 1368.

Cooper. K.A. (1948). Dhar, M.L., Hughes, E.D., Ingold, C.K., Macnulty, B.J. and Woolf, L.I. J. Chem. Sco., 2043.

Drusnel. (1915). Am. J. Sc., 40, 643.

Edward. J.T. and Meacook. S.C.R. (1957). J. Chem. Soc., 2000.

Gupta. L.N. (1994). Ph.D. Thesis, Jiwaji University, Gwalior. 
Hammett. L.P. and Deyrup. A.J. (1932). J. Amer. Chem. Soc., 54, 2721.

Hudson and Keavy. (1956). J. Chem. Soc., 3629.

Hughes. E.D. and Ingold. C.K. (1935). J, Chem. Soc., 244.

Ingold. C.K. (1953). Structure and Mechanism in Organic Chemistry, Bell and Sons, London, 310-345.

Ingold. C.K. (1973). Theoretical Principle of organic chemistry (Translated in Russian) Izd, Miv. Moscow P. 974.

Jeneks. William. P. and Gilchrist. (1965). Mary, J. Am. Chem. Soc. 87 3199-3208.

Kasparek. Frantisek. (1988). Acta, Univ., P.laeki, Olomue, fac, Resum Nat, 91 (Chem 27) 29-33 (Eng.).

Kushwaha. R.S. and Mhala, M.M. (1989). Indian J. of Chem., Vol. 28-A, P-420-421.

Kushwaha. R.S. (1985). Tiwari, B.K., Jagdale, M.H., Salunkhe, M.N. and Baraskar, U.K., J. of Shivaji Univ., Kolhapur, 270.

Kushwaha. R.S. (1986). Tiwari, B.K. and Singh P. Acta Ciencia Indica, Vo., XII C. No. 4, 207.

Kushwaha. R.S. (1988). Tiwari, B.K. and Singh, P. Journal of India Council of Chemists, Vol. No. 3.

Laidler. K.C. and Eyring. H. (1941). The theory of Rate process N.Y., 413-417.

Leffter. J.E. and Grunwald E. (1963). The Rates and Equilibria of Organic Reactions, John Wiley and Sons. INC., N.Y., $177,286$.

Long. F.A. and Paul. M.A. (1957). Chem. Revs., 57, 2-14.

Mhala M.M. and Killendar. A.V. (1967). J. Indian Chem. Soc., Vol III.

Mhala. M.M. (1968). Patwardhan, M.D. Indian J. Chem., 6. No. 12, 704-707.

Mhala. M.M. (1969). Patwardhan, M.D. and Kasturi (Mrs) G. Indian J. Chem., 7, 145-148.

Numkar. M. J. (2004). Pandey. R. and Kalamse. G.M., Int. J. Chem. Sci. 2(2). 251.

Pandey. P. (1989). Batra, B.S., Pant, B.P., Tetrahedron letters, 30, 1987.

Patil. (Mrs) R. (1996). Shinde, C.P., Dass, K.B. and Chauhan, J.s. Asian J., of Chem., 8, No. (2). 197-200.

Pearson. R.G. (1952). Chem. Phys., 20, 1478.

Plimmer and Burch. (1929). J, Che., Soc. 279, 292.

Prakash. O. (2003). Sindal. R.S. and Sharma, P.K. Int. J. Chem. Scie., 1(4). 411.

Rosenthal. D. and Taylor. I.T. (1957). J. Amer. Chem. Soc., 79, 2684.

Rylander and Tarbell. (1950). J. Amer. Chem., Soc. 72, 3021.

Schaefgen. (1948). J. Amer. Chem. Soc., 70, 1308.

Shinde. (1986). C.P. Nikam, A.R. and Mhala, M.M. Acta Ciencia Indica, Vol. XII C.No. 1, 46.

Thain. E.M. (1957). J. Chem. Soc, 4694-4699.

Tiwari. B.K. (1998). Chaturvedi (Miss) Kumud, Chaudhary, A., Upadhyaya. R.S. and Dixit, M. Acta Ciencia Indica, Vol. 24-C, No.3, 083.

Tiwari. B.K. (1998). Chaudhary, A. and Dixit, D.K. Acta Ciencia Indica, Vol. XXIV. C. No. 015.

Tiwari. B.K. (2000). Chaturvedi, (Miss). Kumud, Chaudhary. A., Acta Ciencia Indica., Vol. XXVI C. No.2, 053.

Zucker. L. and Hammett. P. (1939). J. Amer. Chem. Soc., 61, 2791.

Table 1. Acid hydrolysis $(3 \mathrm{M}-\mathrm{HCl})$ of the triester

\begin{tabular}{|c|c|c|c|c|}
\hline Time (min) & Optical density $(\mathrm{x})$ & $\mathrm{a}-\mathrm{x}$ & $\log \mathrm{K}_{\mathrm{e}}$ & $10^{3} \mathrm{~K}_{\mathrm{e}}\left(\mathrm{min}^{-1}\right)$ \\
\hline 25 & 0.04 & 0.38 & $\overline{3} .6381$ & 4.35 \\
\hline 57 & 0.09 & 0.33 & $\overline{3} .6263$ & 4.23 \\
\hline 95 & 0.15 & 0.27 & $\overline{3} .6301$ & 4.27 \\
\hline 205 & 0.20 & 0.22 & $\overline{3} .6312$ & 4.28 \\
\hline 225 & 0.26 & 0.16 & $\overline{3} .6324$ & 4.29 \\
\hline 310 & 0.31 & 0.11 & $\overline{3} .6357$ & 4.32 \\
\hline
\end{tabular}

Average value of $\mathrm{K}_{\mathrm{e}}=4.29 \times 10^{-3} \mathrm{~min}^{-1}$ 
Table 2. Rates of hydrolysis (in $\mathrm{min}^{-1}$ ) of Tri-2,5-diethoxyaniline phosphate at hydrochloric acid concentrations at $98^{0} \mathrm{C}$ (30\% dioxane $\mathrm{v} / \mathrm{v}$ )

\begin{tabular}{|c|c|c|}
\hline Medium HCI (M) & $10^{3} \mathrm{Ke}$ & $5+\log \mathrm{K}_{\mathrm{e}}$ \\
\hline 0.01 & 2.01 & 2.30 \\
\hline 0.05 & 2.06 & 2.31 \\
\hline 0.1 & 2.11 & 2.32 \\
\hline 0.5 & 2.52 & 2.40 \\
\hline 1.0 & 2.83 & 2.45 \\
\hline 1.5 & 3.32 & 2.52 \\
\hline 2.0 & 3.70 & 2.57 \\
\hline 2.5 & 3.94 & 2.60 \\
\hline 3.0 & 4.29 & 2.63 \\
\hline 3.5 & 4.60 & 2.66 \\
\hline 4.0 & 4.91 & 2.69 \\
\hline 4.5 & 4.20 & 2.62 \\
\hline 5.0 & 3.71 & 2.56 \\
\hline
\end{tabular}

Table 3. Acid hydrolysis of Tri-2,5-diethoxyaniline phosphate at constant ionic strengths at $98^{0} \mathrm{C}$

\begin{tabular}{|c|c|c|c|}
\hline \multirow{2}{*}{$\begin{array}{c}\text { Ionic } \\
\text { strength }(\mu)\end{array}$} & \multicolumn{2}{|c|}{ Composition } & \multirow{1}{*}{$\begin{array}{c}10^{3} \mathrm{~K}_{\mathrm{e}} \\
\operatorname{expt}\left(\mathrm{min}^{-1}\right)\end{array}$} \\
\cline { 2 - 3 } 1 & $\mathrm{HCI}(\mathrm{M})$ & $\mathrm{NaCI}(\mathrm{M})$ & 2.35 \\
& 0.4 & 0.6 & 2.50 \\
& 0.6 & 0.4 & 2.65 \\
\hline \multirow{3}{*}{2} & 0.8 & 0.2 & 2.50 \\
& 0.7 & 1.3 & 2.75 \\
& 1.0 & 1.0 & 2.90 \\
\hline \multirow{3}{*}{3} & 1.4 & 0.6 & 2.65 \\
& 1.2 & 1.8 & 2.95 \\
& 1.8 & 1.2 & 3.30 \\
\hline
\end{tabular}

Table 4. Specific acid catalysed rates for the hydrolysis of Tri-2,5-diethoxyaniline phosphate at $98^{\circ} \mathrm{C}$

\begin{tabular}{|c|c|c|c|c|}
\hline $\begin{array}{c}\text { Ionic strength } \\
(\mu)\end{array}$ & $\begin{array}{c}10^{3} \mathrm{~K}_{\mathrm{H}}^{+} \\
\left(\mathrm{min}^{-1} \mathrm{~mole}^{-1} 1\right)\end{array}$ & $5+\log \mathrm{K}_{\mathrm{H}}^{+}$ & $\begin{array}{c}103 \mathrm{~K}_{\mathrm{N}} \\
\left(\mathrm{min}^{-1}\right)\end{array}$ & $5+\log \mathrm{K}_{\mathrm{N}}$ \\
\cline { 1 - 3 } 1 & 0.789 & 1.89 & \multirow{2}{*}{2.0} & 2.301 \\
\hline 2 & 0.694 & 1.84 & & \\
\hline 3 & 0.526 & 1.71 & \\
\hline
\end{tabular}


Table 5. Calculated and experimental rates $\left(\right.$ in $\mathrm{min}^{-1}$ ) for the hydrolysis of Tri-2,5-diethoxyaniline phosphate at $98^{0} \mathrm{C}$ $\left(10^{3} \mathrm{~K}_{\mathrm{N}}=2\right)$

\begin{tabular}{|c|c|c|c|}
\hline $\begin{array}{c}\text { Acid HCI } \\
(\mathrm{M})\end{array}$ & $10^{3} \mathrm{~K}_{\mathrm{H}}{ }^{+} \mathrm{C}_{\mathrm{H}}{ }^{+}$ & $10^{3} \mathrm{~K}_{\mathrm{e}}$ & $10^{3} \mathrm{~K}_{\mathrm{e}}$ \\
\hline 0.01 & calc & calc & 2.01 \\
\hline 0.05 & 0.009 & 2.009 & 2.06 \\
\hline 0.1 & 0.047 & 2.047 & 2.11 \\
\hline 0.5 & 0.095 & 2.095 & 2.52 \\
\hline 1.0 & 0.475 & 2.475 & 2.83 \\
\hline 1.5 & 0.885 & 2.885 & 3.32 \\
\hline 2.0 & 1.280 & 3.280 & 3.70 \\
\hline 2.5 & 1.643 & 3.643 & 3.94 \\
\hline 3.0 & 1.979 & 3.979 & 4.29 \\
\hline 3.5 & 2.287 & 4.287 & 4.60 \\
\hline 4.0 & 2.570 & 4.570 & 4.91 \\
\hline 4.5 & 2.830 & 4.830 & 4.20 \\
\hline
\end{tabular}

$\mathrm{a}_{\mathrm{N}}=1$

$\mathrm{b}_{\mathrm{N}}=2 \quad$ in eq. (6)

Table 6. Hammett, Zucker-Hammett, Bunnett and Bunnett and Olsen plot data for the acid hydrolysis of tri-2,5-diethoxyaniline phosphate at $98^{\circ} \mathrm{C}$

\begin{tabular}{|c|c|c|c|c|c|c|c|c|}
\hline $\begin{array}{c}\mathrm{HCI} \\
(\mathrm{M})\end{array}$ & $\begin{array}{c}\mathrm{Log} \\
\mathrm{C}_{\mathrm{H}}^{+}\end{array}$ & $\begin{array}{c}10^{3} \mathrm{~K}_{\mathrm{e}} \text { expt } \\
\left(\mathrm{min}^{-1}\right)\end{array}$ & $5+\log \mathrm{K}_{\mathrm{e}}$ & $\begin{array}{c}5+\log \\
\mathrm{K}_{\mathrm{e}}-\log \\
\mathrm{C}_{\mathrm{H}}{ }^{+}\end{array}$ & $-\mathrm{H}_{0}{ }^{*}$ & $\begin{array}{c}5+\mathrm{H}_{0}+ \\
\log \mathrm{K}_{\mathrm{e}}\end{array}$ & $\begin{array}{c}-\log \\
\left(\mathrm{a}_{\mathrm{H} 20}\right)^{*}\end{array}$ & $\begin{array}{c}-\left(\mathrm{H}_{0}+\log \right. \\
\left.\mathrm{C}_{\mathrm{H}}\right)\end{array}$ \\
\hline 1.0 & 0.00 & 2.83 & 2.45 & 2.45 & 0.20 & 2.25 & 0.017 & 0.20 \\
\hline 1.5 & 0.18 & 3.32 & 2.52 & 2.34 & 0.47 & 2.05 & 0.027 & 0.29 \\
\hline 2.0 & 0.30 & 3.70 & 2.57 & 2.27 & 0.69 & 1.88 & 0.039 & 0.39 \\
\hline 2.5 & 0.40 & 3.94 & 2.60 & 2.20 & 0.87 & 1.73 & 0.053 & 0.47 \\
\hline 3.0 & 0.48 & 4.29 & 2.63 & 2.15 & 1.05 & 1.58 & 0.070 & 0.57 \\
\hline 3.5 & 0.54 & 4.60 & 2.66 & 2.12 & 1.23 & 1.43 & 0.087 & 0.69 \\
\hline 4.0 & 0.60 & 4.91 & 2.69 & 2.09 & 1.40 & 1.29 & 0.107 & 0.80 \\
\hline 4.5 & 0.65 & 4.20 & 2.62 & 1.97 & 1.58 & 1.04 & 0.130 & 0.93 \\
\hline 5.0 & 0.70 & 3.71 & 2.56 & 1.86 & 1.76 & 0.80 & 0.155 & 1.06 \\
\hline
\end{tabular}

* reference 42 
Table 7. Zucker-Hammett plot data for the acid hydrolysis of Tri-2,5-diethoxyaniline phosphate at $98^{0} \mathrm{C}$

\begin{tabular}{|c|c|c|c|c|c|c|c|}
\hline $\begin{array}{l}\mathrm{HCI} \\
(\mathrm{M})\end{array}$ & $\begin{array}{l}\log \\
\mathrm{C}_{\mathrm{H}}^{+}\end{array}$ & $\begin{array}{l}10^{3} \mathrm{~K}_{\mathrm{e}} \\
\left(\mathrm{min}^{-1}\right) \\
\end{array}$ & $\begin{array}{c}5+\log \\
\mathrm{K}_{\mathrm{e}}\end{array}$ & $\begin{array}{c}10^{3} \mathrm{~K}_{\mathrm{H}}^{+} \mathrm{C}_{\mathrm{H}}^{+} \\
\left(\mathrm{min}^{-1}\right)\end{array}$ & $\begin{array}{c}5+\log \\
\mathrm{K}_{\mathrm{H}}^{+} \mathrm{C}_{\mathrm{H}}^{+}\end{array}$ & $-\mathrm{b}_{\mathrm{H}}^{\prime}{ }^{+} \mu$ & $\begin{array}{c}5-\mathrm{b}_{\mathrm{H}}^{\prime}{ }^{+} \mu+\log \\
\mathrm{K}_{\mathrm{H}}^{+} \mathrm{C}_{\mathrm{H}}^{+}\end{array}$ \\
\hline 1.0 & 0.00 & 2.83 & 2.45 & 0.88 & 1.94 & 0.03 & 1.97 \\
\hline 1.5 & 0.18 & 3.32 & 2.52 & 1.28 & 2.10 & 0.04 & 2.15 \\
\hline 2.0 & 0.30 & 3.70 & 2.57 & 1.64 & 2.21 & 0.06 & 2.28 \\
\hline 2.5 & 0.40 & 3.94 & 2.60 & 1.97 & 2.29 & 0.08 & 2.37 \\
\hline 3.0 & 0.48 & 4.29 & 2.63 & 2.28 & 2.35 & 0.09 & 2.45 \\
\hline 3.5 & 0.54 & 4.60 & 2.66 & 2.57 & 2.41 & 0.11 & 2.52 \\
\hline 4.0 & 0.60 & 4.91 & 2.69 & 2.83 & 2.45 & 0.13 & 2.58 \\
\hline 4.5 & 0.65 & 4.20 & 2.62 & 3.06 & 2.48 & 0.14 & 2.63 \\
\hline 5.0 & 0.70 & 3.71 & 2.56 & 3.28 & 2.51 & 0.16 & 2.67 \\
\hline
\end{tabular}

Table 8. Arrhenius plot data (experimental results) for the hydrolysis of Tri-2,5-diethoxyaniline phosphate in acid medium (HCI); $\mathrm{t}$ in $\mathrm{C}$ and $\mathrm{K}_{\mathrm{e}}$ in $\min ^{-1}$

\begin{tabular}{|c|c|c|c|c|}
\hline \multirow{2}{*}{$\begin{array}{c}\text { Temp } \\
\mathrm{t}\end{array}$} & \multicolumn{2}{|c|}{$3 \mathrm{M}$} & \multicolumn{2}{|c|}{$5 \mathrm{M}$} \\
\hline & $10^{3} \mathrm{~K}_{\mathrm{e}}$ & $5+\log K_{e}$ & $10^{3} \mathrm{~K}_{\mathrm{e}}$ & $5+\log \mathrm{K}_{\mathrm{e}}$ \\
\hline 80 & 2.18 & 2.34 & 1.81 & 2.26 \\
\hline 90 & 3.01 & 2.48 & 2.39 & 2.38 \\
\hline 98 & 4.29 & 2.63 & 3.71 & 2.56 \\
\hline
\end{tabular}

Table 9. Arrhenius parameters for the hydrolysis of Tri-2,5-diethoxyaniline phosphate in acid medium

\begin{tabular}{|c|c|c|c|c|c|}
\hline $\begin{array}{c}\text { HCI } \\
(\mathrm{M})\end{array}$ & Slope & Intercept & E k cal mole & A & $-\Delta \mathrm{S}^{\#}$ \\
\hline 3 & -2217.73 & 8.6089 & 10.14 & 67.725 & 52.58 \\
\hline 5 & -2502.56 & 9.3125 & 11.44 & 342.254 & 49.38 \\
\hline
\end{tabular}




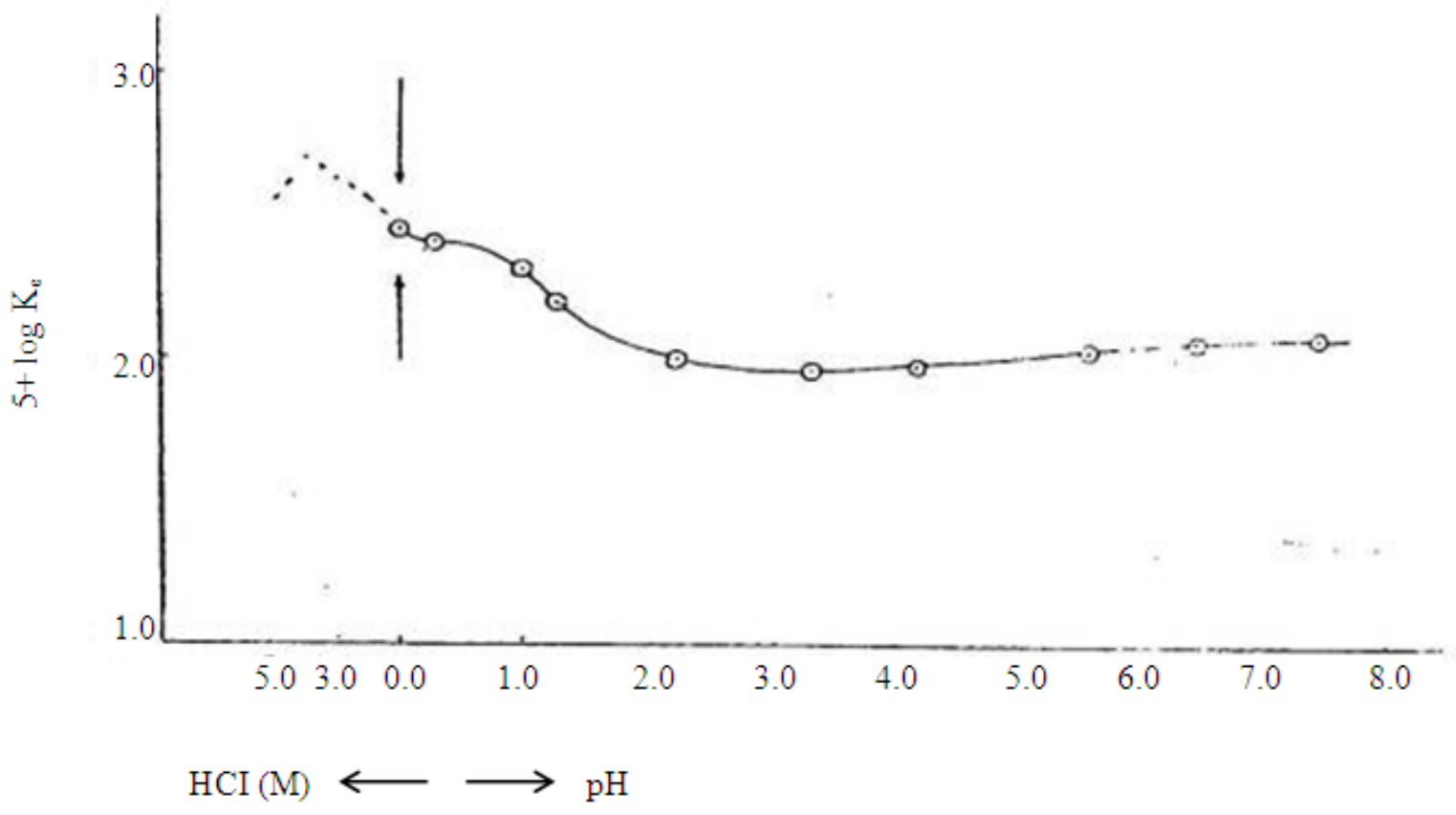

Figure 1. Log rate- (acid, $\mathrm{pH}$ ) profile for the hydrolysis of Tri-2,5-diethoxyaniline phosphate at $98^{\circ} \mathrm{C}$

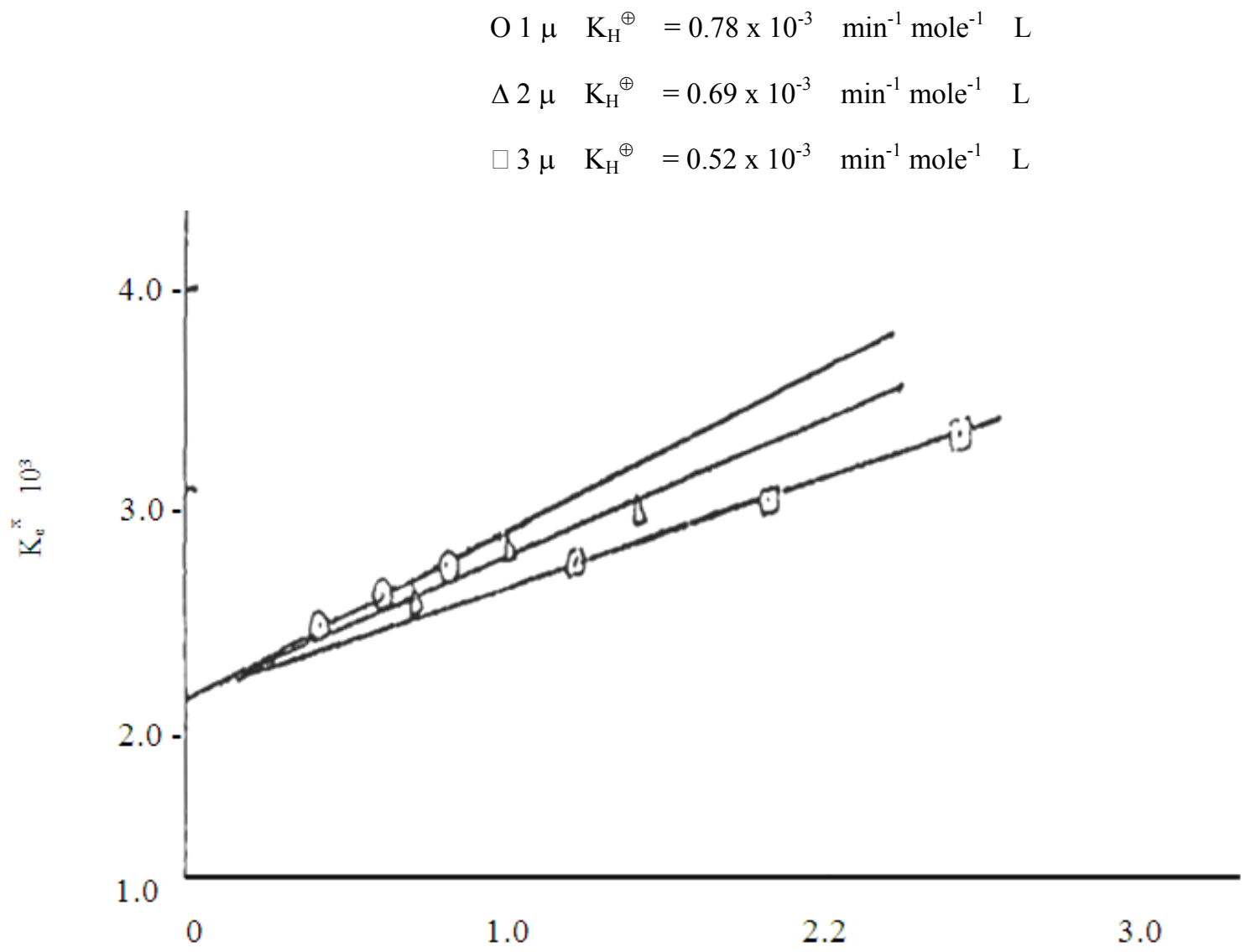

Figure 2. Acid-hydrolysis of Tri-2,5-diethoxyaniline phosphate at constant ionic strengths at $98^{\circ} \mathrm{C}$ 


$$
\begin{array}{lll}
5+\log \mathrm{K}_{\mathrm{H}^{\oplus}}^{\oplus} & = & 1.98 \text { (the } \mathrm{Y} \text { - intercept) } \\
\mathrm{b}_{\mathrm{H}} \ominus & = & -0.07 \text { (the slope) }
\end{array}
$$

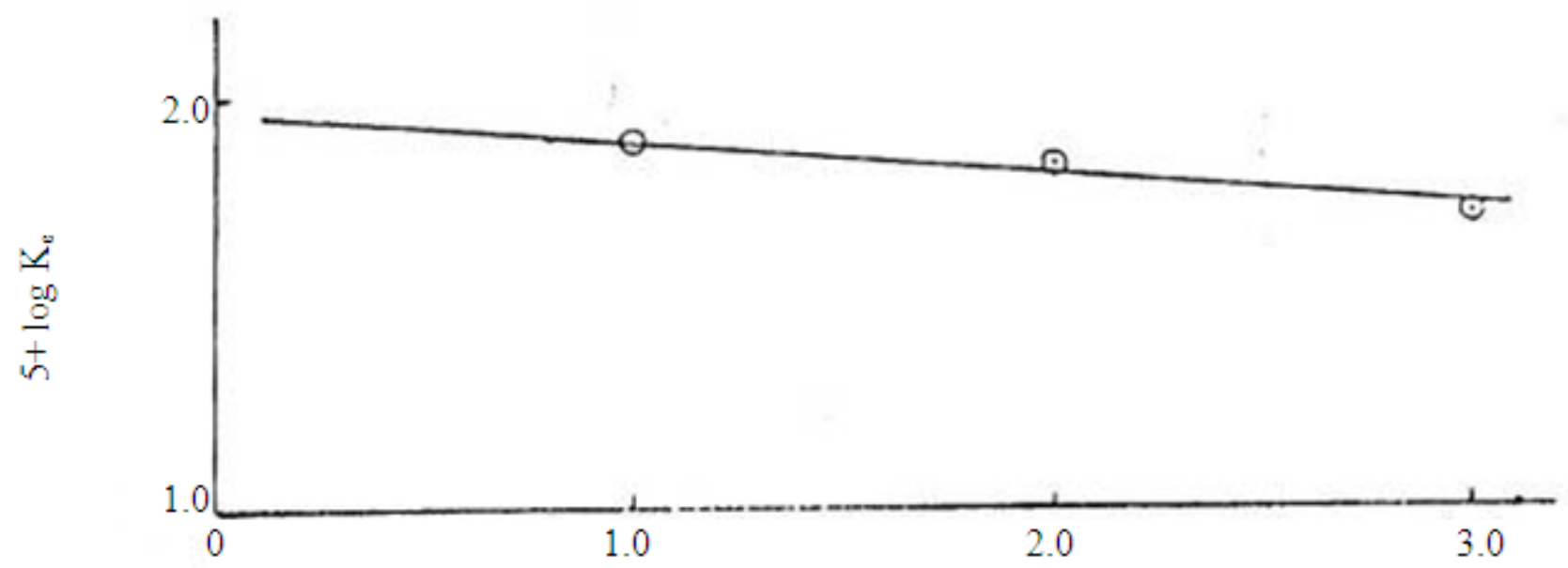

Figure 3. Acid hydrolysis of Tri-2,5-diethoxyaniline phosphate

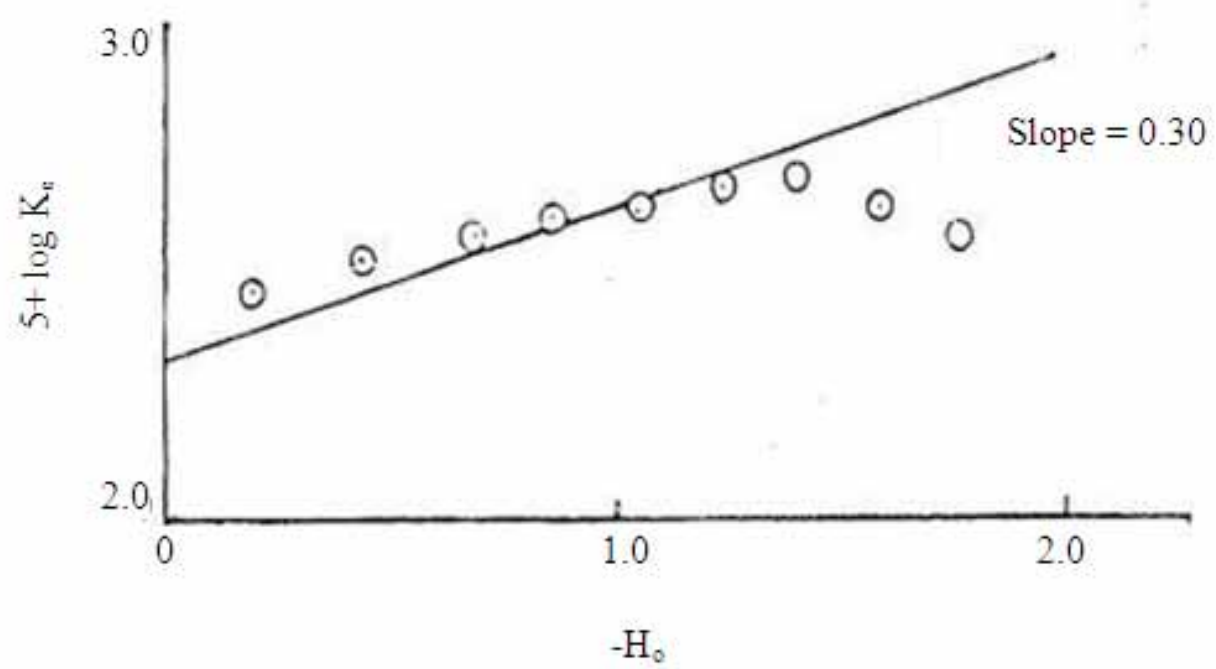

Figure 4. Hammett - plot of the acid catalysed hydrolysis of Tri-2,5-diethoxyaniline phosphate at $98^{\circ} \mathrm{C}$ 


$$
\begin{array}{ll}
\odot 5+\log \mathrm{K}_{\mathrm{s}} \text { (expt) vs } \log \mathrm{C}_{\mathrm{H}}^{\ominus} & \text { slope }=0.41 \\
\Delta 5+\log \mathrm{K}_{\mathrm{H}}^{\ominus} \mathrm{C}_{\mathrm{H}}^{\ominus}-\mathrm{b}_{\mathrm{H}}{ }^{\ominus} \mu \text { vs } \log & \text { slope }=1.0 \\
\Delta \text { [acid corrected graph] } &
\end{array}
$$

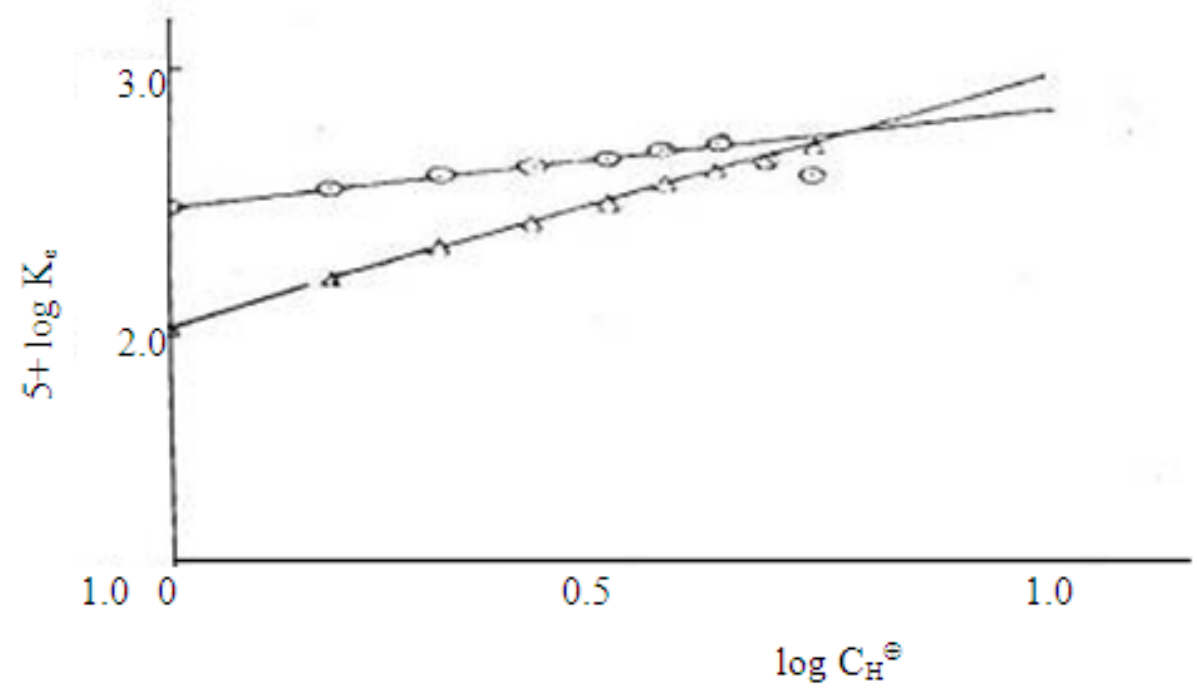

Figure 5. Zucker - Hammett plot for the hydrolysis of Tri-2,5-diethoxyaniline phosphate at $98^{\circ} \mathrm{C}$

$$
\begin{array}{ll}
\odot\left(5+\log \mathrm{K}_{\mathrm{a}}+\mathrm{H}_{\mathrm{o}}\right) \text { vs }\left(-\log \mathrm{a}_{2} \mathrm{O}\right) & \text { slope }(\mathrm{w})=9.09 \\
\Delta\left(5+\log \mathrm{K}_{\mathrm{a}}-\log \mathrm{C}_{\mathrm{H}^{+}}\right) \text {vs }\left(-\log \mathrm{a}_{\mathrm{H}, \mathrm{O}}\right) & \text { slope }\left(\mathrm{w}^{*}\right)=3.75
\end{array}
$$

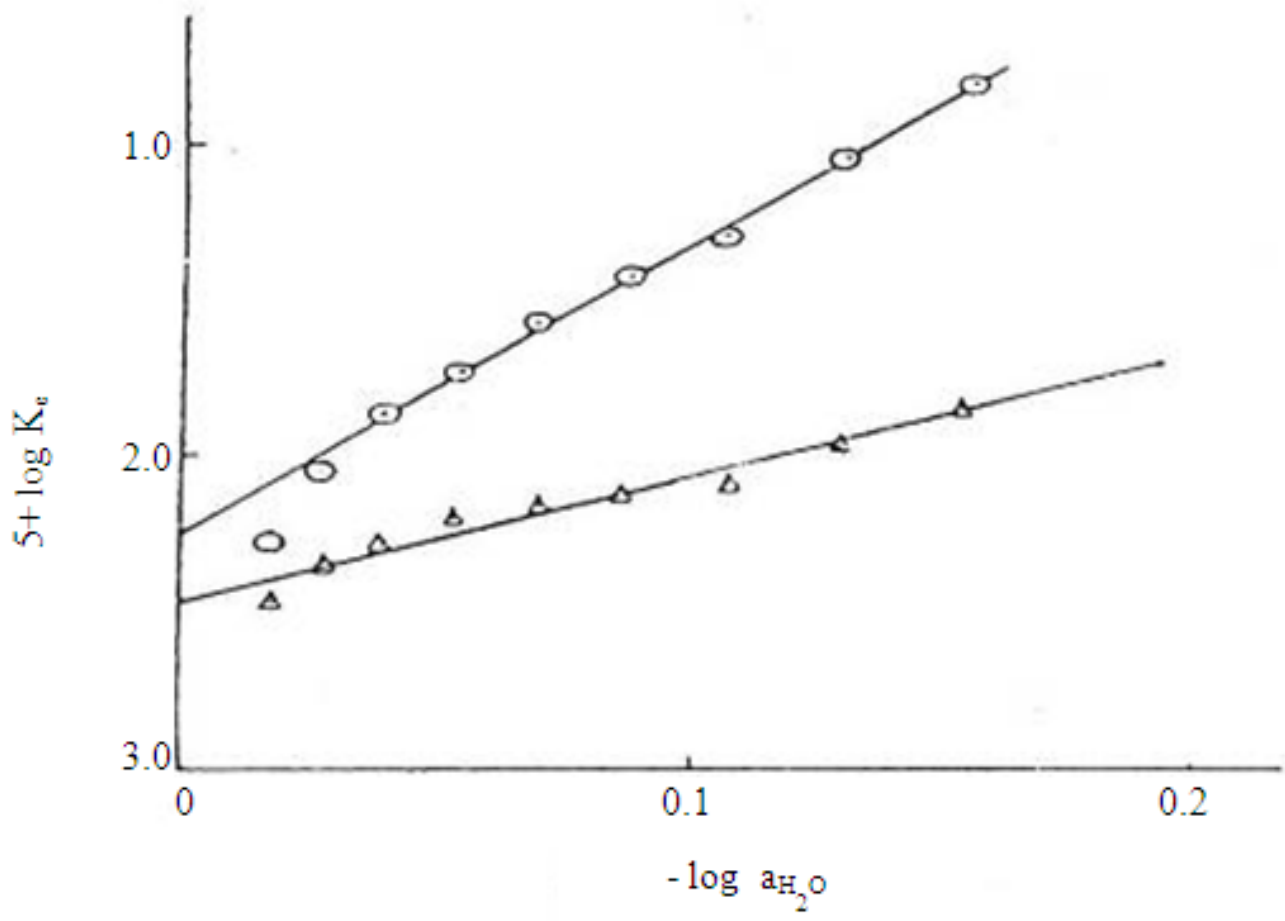

Figure 6. Bunnett plots for the hydrolysis of Tri-2,5-diethoxyaniline phosphate at $98^{\circ} \mathrm{C}$ 


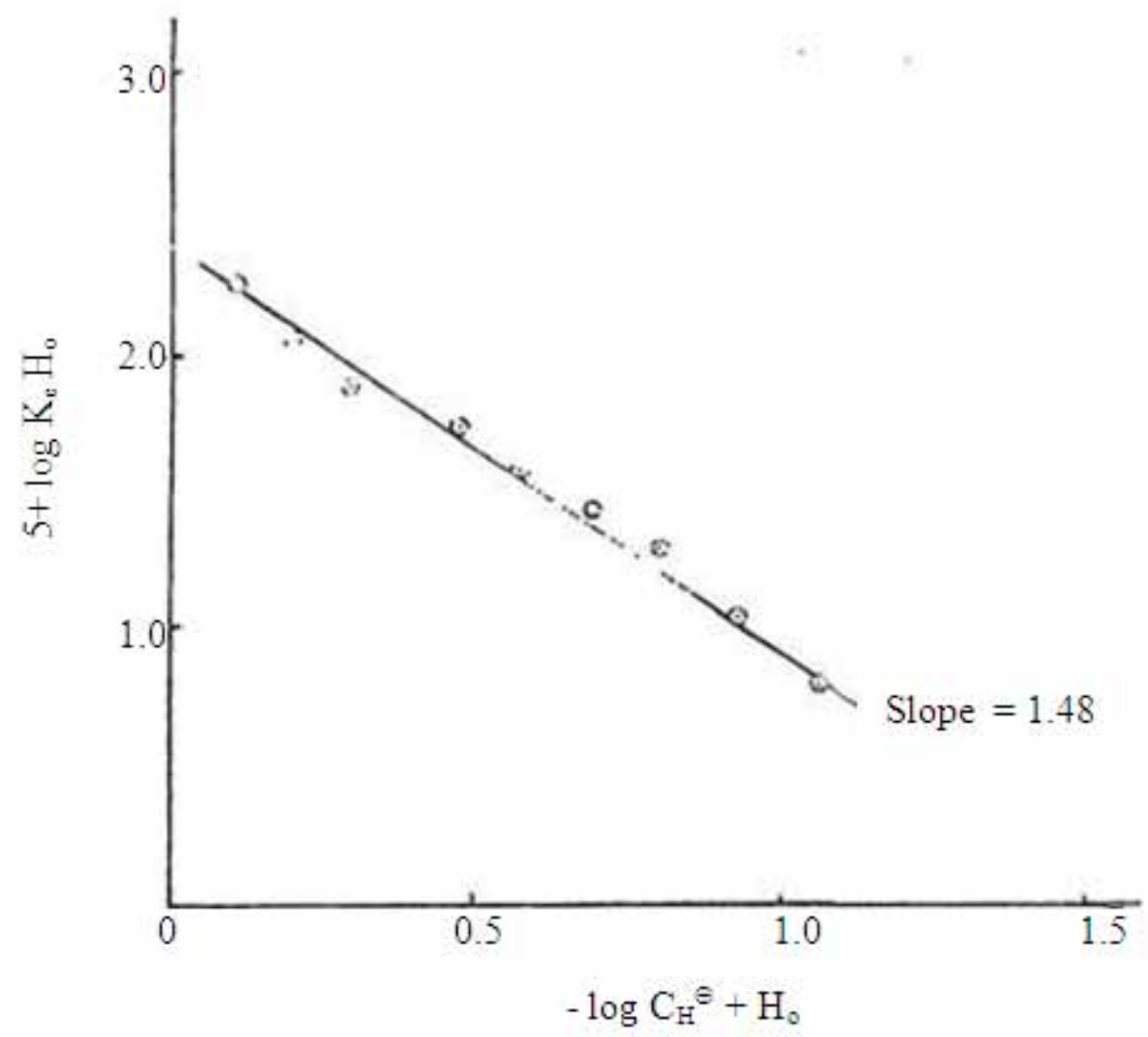

Figure 7. Bunnett and O1sen plot for the hydrolysis of Tri-2,5-diethoxyaniline phosphate at $98^{\circ} \mathrm{C}$. 